\section{Edycasáa

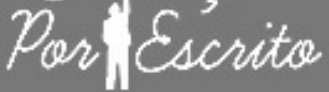

ARTIGO

\section{Editor}

Alexandre Anselmo Guilherme PUCRS, RS, Brasil

\section{Editor Assistente}

Cibele Cheron

PUCRS, RS, Brasi

\section{Editores Associados}

Bruno Antonio Picoli

Universidade Federal da Fronteira Sul, Chapecó, SC, Brasil

Pricila Kohls dos Santos Universidade Católica de Brasília, Brasília, DF, Brasil

Renato de Oliveira Brito

Universidade Católica de Brasilia, Brasilia, DF, Brasil

Elisa Ustarroz

PUCRS, Porto Alegre, RS, Brasil

\section{ISSN 2179-8435}

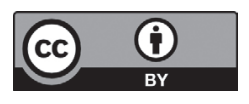

Este artigo está licenciado sob forma de uma licença Creative Commons Atribuiçăo 4.0 Internacional, que permite uso irrestrito, distribuicão e reproduçáa
em qualquer meio, desde que a publicacăa original seja corretamente citada.

\title{
Metodologias ativas e engajamento docente: uma reflexão sobre as dificuldades enfrentadas pelos professores da educação superior
}

Active methodologies and teacher engagement: a reflection on the difficulties faced by higher education teachers

\author{
Ernandes Rodrigues do Nascimento 1 \\ Maria Auxiliadora Padilha $\odot^{2}$ \\ Cristiane Lucia da Silva $\mathbb{1}^{3}$ \\ Fábio Leandro Melo Ramo dos Anjos $\oplus^{4}$ \\ ${ }^{1}$ Faculdade Imaculada Conceição do Recife, Recife, PE, Brasil. \\ 2Universidade Federal de Pernambuco, Recife, PE, Brasil. \\ ${ }^{3}$ Instituto Federal de Educação, Ciência e Tecnologia de Pernambuco, Recife, PE, Brasil. \\ ${ }^{4}$ Faculdade Imaculada Conceição do Recife, Recife, PE, Brasil
}

\section{RESUMO}

O objetivo geral deste estudo foi conhecer o engajamento dos docentes durante a transição dos modelos tradicionais de ensino para o uso de metodologias inovadoras em suas aulas no ensino superior. E, os específicos, foram: conhecer as dificuldades dos docentes durante o planejamento e a realização de aulas inovadoras; descrever a percepção dos docentes sobre o uso de métodos inovadores de ensino e aprendizagem; e apresentar como os docentes se engajam para aprender novos métodos de ensino. Nos últimos anos, muito tem se discutido sobre o uso de metodologias ativas na educação superior. Todavia, parece que há mais teoria que prática efetiva entre os professores. Quais dificuldades os docentes enfrentam ao tentar abandonar o modelo tradicional de ensino e partir para o modelo disruptivo? Quais as percepções dos docentes em relação ao uso das metodologias ativas? Como os docentes se engajam para aprender e praticar novos métodos de ensino e aprendizagem? Diante das inquietações dos pesquisadores, o presente estudo qualitativo foi realizado por meio de um curso de extensão, o qual possibilitou a coleta de dados a partir da sala de aula virtual (Google Classroom), do diário de aprendizagem e dos debates realizados via WhatsApp. Os resultados apresentaram o tempo como um dos maiores problemas vivenciados pelos professores em seu cotidiano, que destacaram pontos positivos e negativos da sua percepção no que se refere ao uso de metodologias ativas e expuseram o seu engajamento docente em relação às mesmas. Palavras-chave: Metodologias ativas. Engajamento docente. Aulas inovadoras. 


\section{ABSTRACT}

The general objective of this study was to know the engagement of teachers during the transition from traditional teaching models to the use of innovative methodologies in their higher education classes. And the specifics: to know the difficulties of teachers during the planning and conducting of innovative classes; describe teachers perceptions of the use of innovative teaching and learning methods; introduce how teachers engage to learn new teaching methods. In recent years, much has been discussed about the use of active methodologies in higher education. However, it seems that there is more theory than effective practice among teachers. What difficulties do teachers face when trying to abandon the traditional teaching model and move to a disruptive model? What are the teachers perceptions regarding the use of active methodologies? How do teachers engage in learning and practicing new teaching and learning methods? Given the researchers concerns, this qualitative study was conducted through an extension course, which enabled the collection of data from the virtual classroom (Google Classroom), the learning diary and the debates conducted via WhatsApp. The results presented time as one of the biggest problems experienced by teachers in their daily lives, which highlighted positive and negative points of their perception regarding the use of active methodologies and exposed their teaching engagement in relation to them.

Keywords: Active methodologies. Teaching engagement. Innovative lessons.

\section{Introdução}

$\mathrm{O}$ contínuo avanço nas Tecnologias Digitais de Informação e Comunicação (TDIC) tem provocado diversas mudanças na sociedade, alterando o comportamento social, como por exemplo: a dependência de muitas pessoas em relação aos smartphones, a necessidade de exposição pessoal por meio de fotos, áudios e vídeos nas redes sociais virtuais, o consumo da própria internet etc. Nos setores profissionais vemos uma grande incorporação das tecnologias digitais, das mais usuais (como uso do WhatsApp para atendimento psicológico) até recursos mais minuciosos e específicos (como aparelhos cirúrgicos de alta precisão). Ao mesmo tempo, outros setores não evoluíram na mesma velocidade, deixando lacunas entre as necessidades dos consumidores e os produtos e serviços que lhes são ofertados.

Nos últimos anos, um exemplo clássico sobre áreas que ainda precisam de mais adaptação para acompanhar a evolução trazida pelas TDIC é a educação, em especial, o ambiente educacional, o qual, segundo Moran (2000; 2015), ainda está estruturado e funcionando como se estivéssemos na Idade Média, em pleno século XXI. Apesar disso, observamos que há iniciativas de professores (BACICH; NETO; TREVISANI, 2015; NASCIMENTO et al., 2016) que buscam mudar essa realidade, discutindo e implementando métodos e as práticas inovadoras de ensino, com o intuito de reduzir o gap (lacuna) existente no ambiente educacional. 
Percebe-se também que o estudante mudou, deixando as práticas acadêmicas atuais deficitárias, pois as escolas e as faculdades já não atendem às suas reais necessidades. Atualmente, os estudantes já fazem uso da convergência digital (JENKINS, 2013) para diversas finalidades, tais como: lazer, trabalho e estudo. Todavia, não se percebe a utilização dos smartphones, das câmeras fotográficas e das filmadoras em sala de aula, integradas ao processo de ensinagem ${ }^{1}$, especialmente na educação superior.

A integração das TDIC no processo de ensinagem pode abrir espaço para o desenvolvimento de metodologias inovadoras, potencializando a aprendizagem do estudante, tais como: sala de aula invertida, rotação por estações, laboratórios rotacionais, educomidia, PBL, TBL, Simulação, Peer Instruction, Gamificação, entre outras possibilidades.

Ressalta-se também que para se inserir novas metodologias de ensino e aprendizagem no contexto educacional, precisa-se do engajamento docente tanto em sua formação contínua, aprendendo novas formas de ensinagem, quanto em sua prática docente em sala de aula, demandando do professor planejamento e ousadia para promover uma aprendizagem mais dinâmica, motivadora, envolvente e com foco na autonomia do aluno, respeitando as suas experiências e atendendo as suas reais necessidades.

Em um cenário em que se exige a transformação do perfil dos profissionais, não somente em relação às ferramentas de trabalho, mas, principalmente em relação à forma como atua e encara a finalidade de suas atuações, o educador está sendo cada vez mais exigido. Formação continuada, atualização constante, novas exigências em sala de aula, tanto dos gestores, como dos pais, alunos e a própria sociedade, garante um clima de tensão na busca pela realização profissional desses. Além de tudo isso, ainda é preciso ter paixão pelo que se faz! Será que esse profissional está estimulado? O que garante o seu engajamento em sala de aula, na busca pela aprendizagem de seus alunos? O que eles estão fazendo para garantir a sua permanência na profissão?

Tantas inquietações nos trouxeram a seguinte questão de pesquisa: como se engajam os professores no processo de transição dos métodos tradicionais de ensino para o uso de metodologias ativas em seu cotidiano?

Paulo Freire (1974) apresenta o professor como mediador na construção do conhecimento, ao qual cabe a tarefa de aprender métodos e técnicas que lhe auxiliem a contribuir para a autonomia do aprendiz em seu desenvolvimento acadêmico e profissional. Ressaltamos que os estudantes do século XXI demandam por aulas motivadoras, que os levem a vivenciar a prática e a relacioná-la às teorias estudadas (BACICH; NETO; TREVISANI, 2015), principalmente, porque as aulas puramente expositivas já não atendem mais aos anseios deles.

\footnotetext{
1 O termo ensinagem está sendo utilizado de acordo com Pimenta e Anastasiou (2005), considerando que este é um processo dialético, caracterizado pela ação conjunta de professor e alunos. mediante tarefas contínuas dos sujeitos no processo educativo.
} 
Para o desenvolvimento dessa pesquisa, tivemos como objetivo geral: conhecer o engajamento dos docentes durante a transição dos modelos tradicionais de ensino para o uso de metodologias inovadoras em suas aulas no ensino superior. Foram nossos objetivos específicos: conhecer as dificuldades dos docentes durante o planejamento e a realização de aulas inovadoras; descrever a percepção dos docentes sobre o uso de métodos inovadores de ensino e aprendizagem; e apresentar como os docentes se engajam para aprender novos métodos de ensino.

\section{Aulas inovadoras e metodologias ativas}

Dentre as diversas mudanças trazidas pelo avanço das Tecnologias Digitais de Informação e Comunicação, encontramos significativas transformações na Educação, integrando as tecnologias digitais no ambiente de ensino e aprendizagem presencial, criando a possibilidade de aulas inovadoras, como no modelo do ensino híbrido, o qual traz uma mescla entre momentos presenciais e virtuais, por meio de recursos online de aprendizagem, tais como: vídeos, podcasts, games, textos, enquetes etc.

$\mathrm{Na}$ atualidade, no Brasil, poucos são os exemplos de cursos totalmente híbridos, tendo apenas alguns cases como um Centro Universitário sediado em Foz do Iguaçu, no Paraná, que transformou os seus cursos de graduação em modelo híbrido, deixando todo o material teórico no ambiente virtual e conduzindo a aula presencial para uma aprendizagem por meio de projetos, uma das metodologias ativas de ensinagem mais comum no Brasil (NASCIMENTO et al., 2016), momento em que os estudantes em equipe e guiados pelo professor, que assume o papel de tutor, resolvem problemas da vida real.

O ensino híbrido traz em seu conceito discussões sobre inovação sustentada e disruptiva (BACICH; NETO; TREVISANI, 2015; CHRISTENSEN; HORN; STAKER, 2013), tem como base a integração das tecnologias digitais utilizadas pelos ambientes educacionais, combinando ações presenciais e online, no qual o educando tenha o controle ou parte dele sobre o tempo, o lugar, o caminho e o ritmo para estudar, para aprender (HORN; STAKER, 2015), ou seja, colocando o estudante como centro desse processo e o professor como mediador, guiando-o em todo o percurso necessário à sua formação (NASCIMENTO et al., 2016).

O ensino inovador busca quebrar o paradigma tradicional, direcionando o centro do processo de formação para o estudante e transformando o professor em um agente de transformação, o qual terá o papel de mentor. Entretanto, faz-se necessário integrar as metodologias ativas de ensino e aprendizagem nos ambientes educacionais inovadores, possibilitando ao docente o uso de métodos e técnicas que conduzam o estudante a aprender fazendo, seja por meio de estudo de caso, role-play ou por resolução de problemas. Em outras palavras, não existe aula inovadora dissociada de metodologias ativas no processo de ensinagem.

Educação Por Escrito, Porto Alegre, v. 10, n. 1, jan.jun. 2019: e31560 
Vários estudos demonstram que a utilização das metodologias ativas motiva e envolve os estudantes em sua formação (BACICH; MORAN, 2018; BACICH; NETO; TREVISANI, 2015), especialmente, por proporcionar uma aprendizagem significativa. Porém, ainda é incipiente a inserção dessas metodologias nas coreografias institucionais ${ }^{2}$, restando a alguns professores que buscam quebrar o paradigma da aula tradicional, fazer por conta própria uma aula diferenciada, correndo o risco de ser repudiado pela gestão da própria instituição de ensino. Isso fica claro quando percebemos as diversas iniciativas em formar professores para uso das metodologias ativas em sala de aula (BACICH; MORAN, 2018; BACICH; NETO; TREVISANI, 2015), por meio de fóruns, congressos, livros e pesquisas científicas. Resta aos docentes, planejarem as suas aulas inserindo em suas coreografias didáticas ${ }^{3}$ (OSER; BAERISWYL, 2001; ZABALZA, 2005) ambientes de aprendizagem diversificados e métodos ativos, conduzindo o estudante a uma aprendizagem significativa.

\section{Planejamento e realização das aulas}

Ferreira afirma que planejar significa "elaborar um plano" (2011, p. 590), o qual, por sua vez significa "conjunto de métodos para a execução dum empreendimento ou projeto; intento, propósito" (2011, p.591). O autor ainda esclarece que empreendimento é um substantivo derivado do verbo empreender que significa "por em execução" (2011, p.280). No campo da educação, planejar se refere às estratégias didáticas e pedagógicas utilizadas pelos docentes na concepção das suas aulas (BARROS, 2014; MORAES; LA TORRE, 2004), inserindo nesse planejamento as suas coreografias didáticas (ZABALZA; ZABALZA CERDEIRIÑA, 2010).

O professor, antes de ir para a sala de aula desenvolve o seu planejamento. Ele pesquisa os conteúdos referentes à sua ementa; coleta dados que estejam relacionados aos conteúdos desejados; analisa-os identificando quais serão mais úteis em suas aulas e os seleciona, compondo o seu material didático para sala aula; define quais métodos serão mais adequados para a construção das competências desejadas; e, identifica quais formas avaliativas serão capazes de mensurar a aprendizagem real dos estudantes.

\footnotetext{
2 "Essa coreografia diz respeito a como a instituição se organiza e disponibiliza as condições necessárias para as coreografias didáticas serem produzidas por professores e alunos nos diversos espaços tempos da universidade. Elas são as políticas de formação de professores e de apoio ao ensino, as condições estruturais e materiais disponíveis para a montagem do cenário das coreografias e, inclusive, o clima organizacional da instituição" (PADILHA; ZABALZA, 2015, p. 21).

3 A coreografia didática é "uma série de passos de dança que satisfaz simultaneamente dois tipos de demandas. Por um lado, o dançarino pode criar livremente dentro do espaço disponível para ele ou ela e expressivamente mostrar uma paleta inteira de arte. Por outro lado, o dançarino é limitado pelas estruturas do ritmo, a estrutura métrica, e da forma profunda da sequência musical" (OSER; BAERISWYL, 2001, p. 1043, tradução nossa).
} 
No primeiro contato dos docentes com os estudantes, é ideal que o professor identifique os estilos de aprendizagem e os conhecimentos prévios dos sujeitos, além das suas experiências e expectativas. Essas ações possibilitarão aos docentes rever o seu planejamento, ajustando-o se for necessário. Ele poderá realizar uma aula personalizada às necessidades dos estudantes, maximizando a sua aprendizagem. Contudo, a realização das aulas exige do docente uma autoavaliação constante, revisando o seu planejamento e ajustando-o às novas necessidades no processo de ensino e de aprendizagem.

Ao realizar as suas aulas, o docente deve ser um observador ativo durante todo o processo de ensinagem, identificando as dificuldades dos estudantes e remodelando as suas estratégias, seja adaptando uma metodologia, modificando-a para melhorar a aprendizagem ou abortando-a durante o percurso. O planejamento e a realização das aulas são atividades constantes no cotidiano do professor, inclusive após o término de uma aula, uma disciplina ou um curso, momento o qual ele deverá refletir sobre as boas-práticas que desenvolveu e as suas dificuldades ou os seus insucessos.

Todavia, para que o docente desenvolva um planejamento eficiente e eficaz e realize aulas significativas para os estudantes, ele deverá estar engajado com a instituição, com os estudantes, com a sua atuação docente, inserindo-se nesse contexto a sua própria motivação em crescer profissionalmente, capacitando-se, ampliando os seus conhecimentos e as suas experiências.

\section{Engajamento docente}

De acordo com Ferreira (2011, p.288), engajar significa: "empenhar-se em algo", dedicar-se a algo de forma voluntária. No campo da educação, Stovall (2003), quando discute engajamento estudantil o define como a relação entre o tempo que o estudante dedica para a realização das tarefas e a sua predisposição para participar nas atividades e interagir com os seus pares. O engajamento também pode ser percebido pela intensidade e dedicação que o estudante está disposto a empregar em seus estudos (CHENG; GONYEA; KUH, 2008; KRAUSE, 2005).

Para Fredricks, Blumenfeld e Paris (2004), engajamento é a forma como os estudantes se comportam, pensam e sentem. Eles dividiram o engajamento estudantil em três tipos: afetivo, cognitivo e comportamental. Muitas vezes o sujeito pode se engajar emocionalmente com uma aprendizagem, mas não cria estratégias cognitivas para desenvolver novas competências ou não se comporta de forma coerente com essas emoções, deixando de aplicar o que aprendeu. Ou seja, não está totalmente engajado.

Há pesquisas (CONNELL; WELLBORN, 1994) que abordam o engajamento como uma forma de enfrentamento do estudante às dificuldades vivenciadas por ele na vida escolar. Outros estudos apresentam a relação entre os tipos 
de engajamento (FINLAY, 2006), discutindo a sobreposição de algumas características entre eles. Também há trabalhos que apresentam escalas para mensurar o engajamento estudantil (BEER; CLARCK; JONES, 2010; CHIN, 2002; STELKO-PEREIRA, 2015), o que é comum em outros países, mas não é uma prática brasileira, ficando os estudos sobre engajamento restrito às pesquisas científicas. E, além de não haver no Brasil um sistema que avalie o engajamento estudantil, também não se encontram na literatura artigos, dissertações, teses, livros que discutam o engajamento do professor em relação ao processo de ensino e de aprendizagem, deixando um gap a ser estudado. Contudo, percebe-se que o professor também pode se engajar afetiva, cognitiva e comportamentalmente, fazendo uma relação com a literatura de engajamento discente.

Quando o docente está engajado emocionalmente, ele demonstra sentimentos de satisfação em: elaborar conteúdos educativos, realizar aulas, orientar os estudantes, aprender com os seus pares etc. Ao mesmo tempo, estando o professor engajado cognitivamente, percebe-se nele o esforço para aprimorar os seus métodos de ensino e aprender os novos conhecimentos, além de desenvolver habilidades e competências essenciais ao seu crescimento profissional. Além disso, o engajamento comportamental faz o docente se envolver nas atividades pedagógicas, sociais e extracurriculares da instituição, melhorando a interação entre ele e seus pares.

Alguns pesquisadores afirmam que as metodologias ativas de ensinagem potencializam o engajamento estudantil (BACICH; MORAN, 2018; BACICH; NETO; TREVISANI, 2015; LEAL; MIRANDA; CASA NOVA, 2018; MORAN, 2000), aumentando a sua motivação para estudar e superar dificuldades no seu processo de aprendizagem, reduzindo as possibilidades de evasão escolar e aumentando as chances de sucesso no mercado de trabalho. Essa mesma motivação pode ser percebida no docente, ao utilizar novos métodos ativos de ensino e aprendizagem em suas aulas e notar a evolução dos seus estudantes.

A lacuna existente na literatura sobre o engajamento docente leva-nos a refletir sobre: as dificuldades que eles enfrentam para ampliar o seu repertório de recursos didáticos e metodológicos, abandonando os métodos tradicionais de ensino com o foco de tornar as suas aulas mais motivantes e significantes para o estudante. Precisa-se, então, conhecer a percepção que o professor tem sobre a sua atuação nos ambientes de aprendizagem e no uso que ele faz das metodologias ativas.

\section{Percepção}

A partir de uma perspectiva abrangente, a percepção pode ser interpretada como uma condição de constante transformação, pois ela depende de outros atores presentes no mundo para se construir. A percepção traz em seu contexto uma expressão criadora, influenciada pelas diversas formas de ver o mundo, refletindo na experiência do sujeito e em sua própria existência. 
Peirce (1958) alia a percepção ao pensamento, que, a partir desse elo, é constantemente transformada. Desta forma, a percepção do professor sofre interferência, também, do contexto em que ele está inserido, imbuindo-se de experiências anteriores, influências externas e pensamentos elaborados em sua mente (PAULUS; FRANK, 2003).

$\mathrm{O}$ docente percebe o processo de ensino e aprendizagem à medida que é impactado pelas emoções, objetivos e interesses presentes em seu contexto, além das suas expectativas em relação à vida pessoal e profissional, construídas, em sua maior parte, por experiências anteriores. Davidoff (2001), explica que, muitas vezes ignoramos as informações trazidas pelos nossos sentidos, fazendo-nos ver o mundo como é útil para nós, não percebendo como exatamente ele é.

À vista disso, o docente percebe a sua atuação por meio do engajamento estudantil nas atividades acadêmicas, a partir da evasão discente em suas aulas, por meio do desempenho dos estudantes, entre outras formas. Porém, a literatura atual não nos apresenta como os professores percebem a inserção das metodologias ativas de ensino e aprendizagem em sua rotina diária, assim como também não trazem a visão do docente em relação à influência desses métodos na aprendizagem efetiva e eficaz dos estudantes, deixando outra lacuna a ser explorada.

\section{Percurso metodológico}

A presente pesquisa foi desenvolvida qualitativamente, a partir de um estudo de caso único (YIN, 2015), o qual foi construído exclusivamente para a pesquisa (CRESWELL, 2010). Elaboramos um curso de extensão com duração de cinco dias, organizado em duas partes: planejamento de aula e estratégias de ensinagem.

Os dados foram coletados por meio de diário de aprendizagem (registro documental dos participantes), discussão em grupo online, por meio do WhatsApp, e observação participante (FLICK, 2009). Para garantir a qualidade da pesquisa, os dados foram triangulados (CRESWELL, 2010) entre os registros documentais, o grupo focal e as observações dos pesquisadores.

Para trabalhar o planejamento, dedicamos os dois primeiros dias do curso, iniciamos com as coreografias didáticas (OSER; BAERISWYL, 2001; PADILHA et al., 2010), destacando as quatros etapas (antecipação, colocação em cena, modelos base e produto), e seguimos para o método Trahentem (ALVES, 2016), o qual utiliza três canvas focados no planejamento de aula, desde a empatia pelo estudante (conhecendo tudo que pode influenciar na sua aprendizagem), passando pela definição das tarefas, até as ações em sala de aula. Neste contexto, o método Trahentem teve o papel de planejamento macro de uma disciplina e as coreografias didáticas guiando a atuação do docente dentro do planejamento.

Para as estratégias de ensinagem, dedicamos os três dias restantes do curso, praticamos: Ensino Híbrido (aula invertida, rotação por estações e laboratórios rotacionais), gamificação, storytelling, aprendizagem em equipe, 
aprendizagem colaborativa, debate e aula dialogada. A integração das TDIC aconteceu a partir do Google for Education (plataforma educacional da Google), utilizando como interface o Google Classroom, além da utilização do smartphone dos alunos, do YouTube e do Canva ${ }^{4}$ (plataforma de design virtual).

O curso foi ofertado com 35 vagas e com as inscrições por meio do Sympla (plataforma de gestão de ingressos, inscrições e eventos). O link de inscrição para o curso foi divulgado nas redes sociais (Facebook e WhatsApp) durante o período de 18 de abril a 7 de maio de 2018. Após a realização das 35 inscrições, quatro inscritos sinalizaram desistência, então, reabrimos as inscrições para a reposição dessas desistências. Optou-se por utilizar o Sympla (Sistema online para gestão e inscrição de eventos) por dar autonomia aos participantes de imprimir o seu próprio certificado, assim como nos ajudou na gestão dos inscritos, emissão das atas de presenças, crachás etc.

Dos inscritos, participaram 28 docentes de diferentes faculdades e universidades locais, com formação em diversas áreas, tais como: Administração, Biomedicina, Fisioterapia, Letras, Física, Odontologia, Pedagogia, Zootecnia etc. Destes, 38\% são doutores, $49 \%$ são mestres e 13\% especialistas. Em relação ao tempo dos docentes no ensino superior, $26 \%$ dos participantes atuam a menos de três anos; $20 \%$ possuem entre 4 e 6 anos de experiência docente; e 54\% têm mais de 6 anos de atuação no ensino superior.

Utilizamos como ambiente virtual de aprendizagem o Google Classroom, no qual criamos a turma "Metodologias Inovadoras - Curso de Extensão" e adicionamos o e-mail de todos os inscritos no Sympla. A única restrição era que o e-mail do participante fosse Gmail (Google), para ter compatibilidade com as ferramentas que foram utilizadas durante o curso. Ao preparar a sala virtual, organizamos, por meio de publicações do tipo posts, em 10 itens, sendo: ementa; e-book sobre educação no ensino superior; coreografias didáticas; estilos de aprendizagem; sugestão de livros; diário de aprendizagem; material didático; aprendizagem experiencial; taxonomia de Bloom; e relato final. Durante o curso, três alunos adicionaram mais três postagens, sendo: materiais compartilhados do Cecine; metodologias ativas; e Casos do Hospital Sírio Libanês.

Os participantes foram orientados a acessarem o diário de aprendizagem todos os dias, após a aula, para registrarem tudo o que aprenderam no dia, não somente no espaço sala de aula, mas em todos os espaços. No último dia, eles deveriam acessar o relato final e descrever todas as suas experiências durante o curso. Para encerrar o curso, foi realizada uma aula invertida no modelo de Grupo Focal utilizando o WhatsApp como canal virtual para a discussão.

Na medida em que os participantes efetivavam as suas inscrições, eram adicionados em um grupo do WhatsApp, intitulado por "Curso_Metodologia_Ativa", o qual teve adesão positiva e troca de experiências, por meio de relatos,

4 Disponível em: https://www.canva.com. Acesso em: 05 jul. 2018. 
discussões e compartilhamento de arquivos, mesmo antes da data de início do curso. Após o primeiro dia de aula, as interações no grupo virtual se intensificaram, estendendo a sala de aula além das paredes físicas, potencializando as aprendizagens, fazendo-se uso do ensino híbrido, e se mantiveram mesmo após o término do curso.

Para as aulas presenciais, utilizou-se uma sala Google, Figura 1, espaço físico mobiliado com mesas retráteis, modulares e bancada, com cadeiras coloridas e em formatos diversos, contendo uma TV de 50", internet Wi-Fi, 34 chromebooks e lousa branca, espaço próprio para utilização de diversas metodologias ativas. O local é chamado de sala Google por causa de uma parceria realizada entre a faculdade que cedeu o espaço para o curso e a empresa Google.

Figura 1. Sala Google

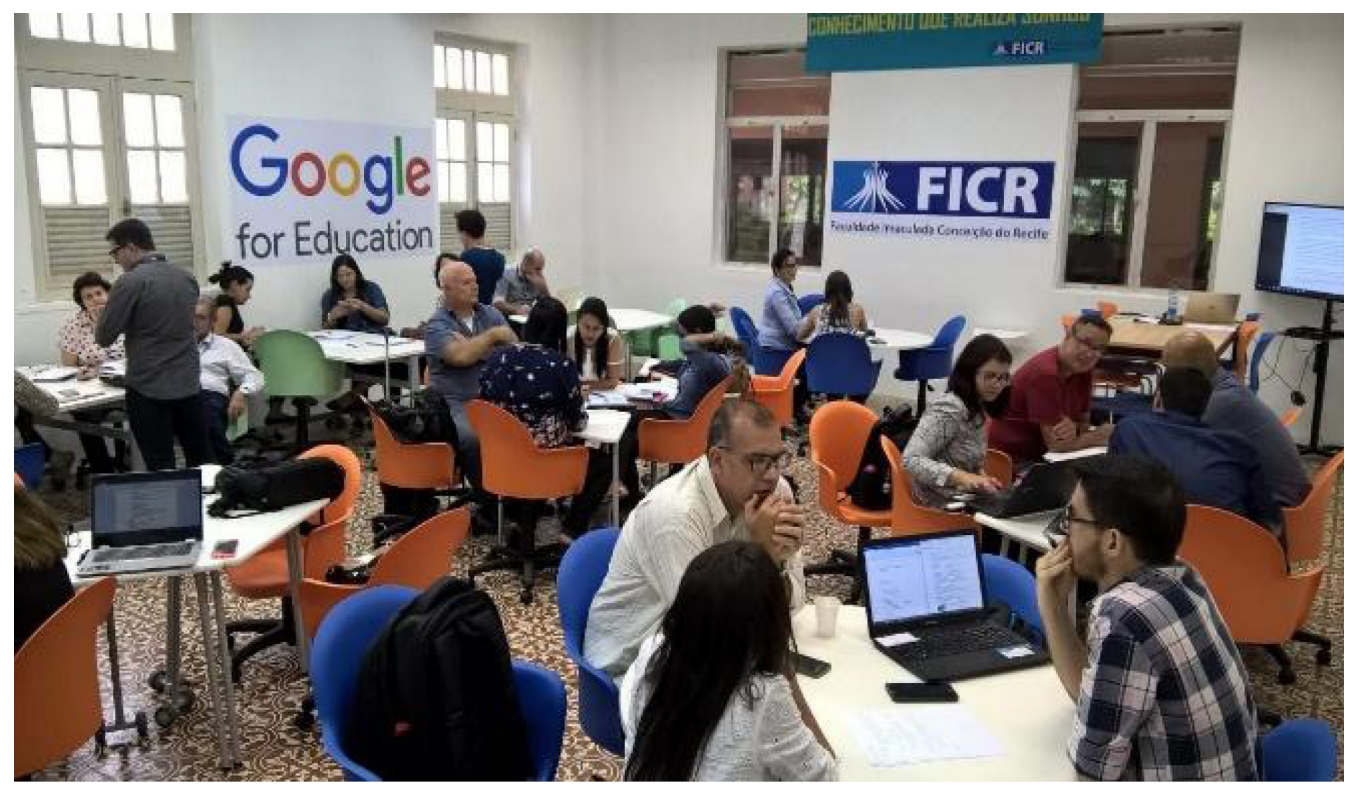

Fonte: Registrada pelos autores (2018). 
As aulas iniciaram no dia 7 de maio, às $13 \mathrm{~h} 30$, sendo realizadas conforme as descrições a seguir. A aula 1 contou com uma apresentação breve de todos os participantes, incluindo os dois professores responsáveis pelo curso. Seguiu-se para a apresentação da proposta do curso e todo o seu planejamento. Em seguida, discutiu-se sobre o ensino híbrido: o que é, como funciona, quais os principais tipos etc. O debate foi possível por ter como base o livro postado no Google Classroom - Ensino Híbrido: uma inovação disruptiva (CHRISTENSEN; HORN; STAKER, 2013), realizando uma aula invertida. Partiu-se, então, para a explanação dos professores sobre o conceito e o funcionamento das coreografias didáticas (PADILHA et al., 2010) e encerramos a aula presencial com uma atividade prática de elaboração de um plano de aula à luz das coreografias didáticas.

Na segunda aula iniciamos com uma retrospectiva do primeiro dia, fazendo um debate sobre o uso das coreografias didáticas e sobre os relatos dos professores no Google Classroom. Após o momento inicial, seguimos para uma segunda aprendizagem, até então desconhecida por todos os participantes, a metodologia Trahentem (ALVES, 2016), a qual é baseada em três canvas, elaborados especificamente para o planejamento de aulas e treinamentos de forma geral. Concluída a exposição dialogada, todos puseram as mãos à obra, momento o qual iniciaram o planejamento de uma aula desde se colocarem no lugar no estudante, empaticamente, pensando em diversos fatores que impactam a sua aprendizagem; em seguida definiram as competências, os objetivos de aprendizagem, as metodologias e as tarefas que os levarão à aprendizagem. Concluídas as atividades, cada equipe apresentou os seus canvas e debatemos sobre o planejamento de cada um, apontando os pontos positivos e a melhorar. Encerramos com uma reflexão sobre as aprendizagens do dia.

Na terceira aula, após uma breve retrospectiva, iniciamos por meio de laboratórios rotacionais, integrando as tecnologias digitais de informação e comunicação fazendo uso do Google Classroom, Formulário Google, Smartphone para gravação de vídeo e o site Canva. A cada meia hora os laboratórios rotacionavam, mudando de equipe, levandoos a experienciar todos os laboratórios. Além de conhecerem os laboratórios rotacionais, aprenderam como integrar a tecnologia em sala de aula. Ao término da aula, como de costume, os grupos expuseram as suas aprendizagens e debatemos sobre os seus posicionamentos.

Iniciamos a quarta aula com a rotação por estações, utilizando gamificação em cada uma das estações. Mas, desta vez, a proposta foi analógica, utilizamos o jogo da trilha, jogo da memória, palavras cruzadas e jogo da forca. Os participantes tiveram que criar os quatro jogos focando uma competência de uma disciplina. Após a construção dos jogos, discutimos o conceito e a aplicabilidade do storytelling e dos games no processo de ensino e de aprendizagem. Todos expuseram as suas percepções e fizemos o encerramento da quarta aula.

A última aula foi invertida, por meio do WhatsApp, momento o qual durou quatro horas contínuas de discussão sobre as aprendizagens, as experiências, as metodologias ativas, o engajamento docente e vários outros tópicos 
que foram surgindo durante a aula. Mesmo após concluído o debate, vários participantes ainda estenderam as suas interações até o final do dia, contabilizando mais de oitos horas de discussão. Essa aula foi desenvolvida em formato de grupo focal, por meio das TDICs, os professores levantam os questionamentos e os sujeitos participaram expondo os seus pontos de vista.

Todo o curso foi documentado pelos professores e participantes, utilizando como base de registro o grupo no WhatsApp, um formulário eletrônico e um diário de aprendizagem - post disponível na sala Google Classroom. Além de diversos comentários dos participantes nas demais postagens nessa sala virtual. Os registros acima citados geraram um arquivo em PDF (compartilhado entre os pesquisadores) e outro impresso e encadernado em três cópias, sendo uma para arquivo da faculdade que apoiou a pesquisa e uma para cada pesquisador.

Os dados coletados foram analisados por meio da análise de conteúdo de Bardin (2011), seguindo as etapas de: a) Pré-análise: Leitura flutuante, escolha dos documentos, formulação das hipóteses e dos objetivos, referenciação dos índices e elaboração de indicadores, e Preparação do material; b) Exploração do material; e c) Tratamento dos resultados obtidos e interpretação. Por fim, categorizamos e analisamos os resultados quantitativa e qualitativamente.

\section{Análise e discussão dos resultados}

A pesquisa resultou em 152 páginas de dados, dos quais foram extraídos e analisados os conteúdos que pudessem responder o problema de pesquisa, o qual trouxe os construtos: engajamento docente; planejamento e realização de aulas por meio de metodologias ativas; e a percepção dos docentes em relação ao uso de metodologias ativas.

Os dados foram organizados e analisados a partir de grupos, categorias e subcategorias, apresentando a sua respectiva frequência relativa. Os Quadros 1 e 2 apresentam o significado atribuído, após a análise, a cada termo utilizado na criação das categorias e subcategorias. 
Quadro 1. Descrição das categorias e subcategorias - parte 1

\begin{tabular}{|c|c|c|c|}
\hline Categoria & Descrição & Subcategoria & Descrição \\
\hline \multirow{2}{*}{ Aprendizagem } & \multirow{2}{*}{$\begin{array}{l}\text { Dificuldade no processo de } \\
\text { aprendizagem: novas metodologias; } \\
\text { formas de planejamento; e formas de } \\
\text { realização de aulas inovadoras }\end{array}$} & Tempo & $\begin{array}{l}\text { Tempo para estudar novos métodos; } \\
\text { Tempo para planejar aulas inovadoras; } \\
\text { Tempo para utilizar metodologias ativas }\end{array}$ \\
\hline & & Compreensão & $\begin{array}{l}\text { Compreender o método; } \\
\text { Compreender a inserção dos métodos em } \\
\text { seu planejamento }\end{array}$ \\
\hline \multirow[b]{2}{*}{ Aplicação } & \multirow{2}{*}{$\begin{array}{l}\text { Dificuldades ao aplicar metodologias } \\
\text { ativas por falta de: habilidade ou porque } \\
\text { questões da cultura tradicional }\end{array}$} & Habilidade & $\begin{array}{l}\text { Falta de habilidade em aplicar novos } \\
\text { métodos em sala de aula }\end{array}$ \\
\hline & & Cultura Tradicional & $\begin{array}{l}\text { Cultura tradicional rígida, impossibilitando } \\
\text { o professor a inserir novos métodos em } \\
\text { suas aulas }\end{array}$ \\
\hline \multirow{4}{*}{$\begin{array}{l}\text { Percepção - Pontos } \\
\text { Positivos }\end{array}$} & \multirow{4}{*}{$\begin{array}{l}\text { Todos os pontos positivos percebidos } \\
\text { pelos docentes na utilização de } \\
\text { metodologias ativas }\end{array}$} & $\begin{array}{l}\text { Melhora o processo de } \\
\text { aprendizagem }\end{array}$ & $\begin{array}{l}\text { Percebem que utilizar métodos ativos } \\
\text { melhora o processo de ensino e } \\
\text { aprendizagem }\end{array}$ \\
\hline & & $\begin{array}{l}\text { Apresenta novas } \\
\text { formas de ensino }\end{array}$ & $\begin{array}{l}\text { Percebem novas formas de ensino a partir } \\
\text { das metodologias ativas }\end{array}$ \\
\hline & & $\begin{array}{l}\text { Cria uma cultura } \\
\text { disruptiva }\end{array}$ & Percebem mudança na cultura tradicional \\
\hline & & $\begin{array}{l}\text { Aumenta o } \\
\text { engajamento estudantil }\end{array}$ & $\begin{array}{l}\text { Percebem aumento no engajamento } \\
\text { estudantil }\end{array}$ \\
\hline \multirow{3}{*}{$\begin{array}{l}\text { Percepção - Pontos } \\
\text { Negativos }\end{array}$} & \multirow{3}{*}{$\begin{array}{l}\text { Todos os pontos negativos percebidos } \\
\text { pelos docentes na utilização de } \\
\text { metodologias ativas }\end{array}$} & Cultura tradicional & $\begin{array}{l}\text { Percebem dificuldades em mudar a } \\
\text { cultura tradicional }\end{array}$ \\
\hline & & $\begin{array}{l}\text { Falta de experiência } \\
\text { dos docentes }\end{array}$ & $\begin{array}{l}\text { Percebem-se sem experiência para utilizar } \\
\text { metodologias ativas }\end{array}$ \\
\hline & & Formação deficitária & $\begin{array}{l}\text { Percebem déficit em sua formação em } \\
\text { relação ao uso de metodologias ativas }\end{array}$ \\
\hline \multirow{4}{*}{ Engajamento - Afetivo } & \multirow{4}{*}{ Quando há envolvimento emocional } & $\begin{array}{l}\text { Satisfação com as } \\
\text { metodologias }\end{array}$ & $\begin{array}{l}\text { Sentem-se felizes ao aprenderem ou } \\
\text { utilizarem novos métodos ativos }\end{array}$ \\
\hline & & $\begin{array}{l}\text { Satisfação na relação } \\
\text { com os pares }\end{array}$ & $\begin{array}{l}\text { Sentem-se felizes em relação a interação } \\
\text { entre seus pares }\end{array}$ \\
\hline & & $\begin{array}{l}\text { Motivação em melhorar } \\
\text { sua prática docente }\end{array}$ & Desejam melhorar suas práticas \\
\hline & & $\begin{array}{l}\text { Curiosidade, Interesse } \\
\text { e Expectativas }\end{array}$ & $\begin{array}{l}\text { Têm curiosidade em aprender novas } \\
\text { metodologias }\end{array}$ \\
\hline
\end{tabular}

Fonte: Elaborado pelos autores (2018). 
Quadro 2. Descrição das categorias e subcategorias - parte 2

\begin{tabular}{|c|c|c|c|}
\hline Categoria & Descrição & Subcategoria & Descrição \\
\hline \multirow{5}{*}{$\begin{array}{l}\text { Engajamento - } \\
\text { Cognitivo }\end{array}$} & \multirow{5}{*}{ Quando há envolvimento cognitivo } & Esforço para aprender & Esforça-se para aprender novos métodos \\
\hline & & $\begin{array}{l}\text { Investimento para } \\
\text { aprender }\end{array}$ & $\begin{array}{l}\text { Dedica tempo para: estudar, buscar novos } \\
\text { materiais e compartilhar o que sabe. }\end{array}$ \\
\hline & & $\begin{array}{l}\text { Compreensão das } \\
\text { ideias complexas }\end{array}$ & Compreende e discute ideias complexas \\
\hline & & $\begin{array}{l}\text { Desenvolvimento de } \\
\text { habilidades mentais }\end{array}$ & $\begin{array}{l}\text { Demonstra esforço mental para aprender } \\
\text { novas habilidades }\end{array}$ \\
\hline & & $\begin{array}{l}\text { Resolução de } \\
\text { problemas }\end{array}$ & Comprometido em resolver problemas \\
\hline \multirow{5}{*}{$\begin{array}{l}\text { Engajamento - } \\
\text { Comportamental }\end{array}$} & \multirow{5}{*}{$\begin{array}{l}\text { Quando há envolvimento } \\
\text { comportamental }\end{array}$} & $\begin{array}{l}\text { Realização das } \\
\text { atividades }\end{array}$ & Realiza atividades para aprender mais \\
\hline & & Interação com os pares & Interage com pares para aprender mais \\
\hline & & Compartilhamento & Compartilha aprendizagens e experiências \\
\hline & & $\begin{array}{l}\text { Busca de novos } \\
\text { materiais }\end{array}$ & Busca novos conteúdos e atualizações \\
\hline & & $\begin{array}{l}\text { Utilização de } \\
\text { metodologias ativas }\end{array}$ & Prática metodologias ativas. \\
\hline
\end{tabular}

Fonte: Elaborado pelos autores (2018).

A próxima subseção analisa e discute as principais dificuldades vivenciadas pelos docentes ao planejarem e executarem as suas aulas à luz das metodologias ativas.

\section{Quais são as principais as dificuldades dos docentes ao planejar e a realizar aulas inovadoras?}

Com base nos dados analisados, os docentes demonstraram dificuldades em duas categorias, uma relacionada ao processo de aprendizagem de novas metodologias de ensino e outra à aplicação desses métodos em suas aulas. Na primeira delas encontramos a falta de tempo necessário para se atualizar e aprender novas formas de ensinagem e a compreensão sobre como empregar os novos métodos. Na segunda, encontramos a falta de habilidade na utilização de metodologias ativas em sala de aula e o enfrentamento à resistência estabelecida pela cultura tradicional. 
O Quadro 3 apresenta as categorias e as suas frequências relativas referentes a cada uma das dificuldades que os docentes possuem ao planejarem e realizarem aulas inovadoras.

Quadro 3. Dificuldades no Planejamento e Execução de aulas inovadoras

\begin{tabular}{|l|l|l|c|}
\hline Grupo & Categoria & Subcategoria & Frequência \\
\hline \multirow{2}{*}{$\begin{array}{l}\text { 1 - Dificuldades dos docentes } \\
\text { em relação ao planejamento e a } \\
\text { realização de metodologias ativas }\end{array}$} & $1.1-$ Aprendizagem & $1.1 .1-$ Tempo & $85 \%$ \\
\cline { 2 - 5 } & $1.2-$ Aplicação & $1.1 .2-$ Compreensão & $15 \%$ \\
\hline
\end{tabular}

Fonte: Elaborado pelos autores (2018).

Os sujeitos compartilharam as suas principais dificuldades ao aprender novas metodologias de ensinagem, as quais foram agrupadas entre falta de tempo para estudar e experimentar outras possibilidades, a compreensão em como as metodologias ativas podem auxiliar no processo de ensino e aprendizagem, a falta de habilidade em aplicálas e a resistência persistente do modelo tradicional. Em relação a dificuldade tempo, um dos participantes do curso disse que precisava multiplicar o seu tempo (SUJEITO 02), enquanto outros disseram que nem sempre há tempo para estudar e ampliar o seu repertório (SUJEITOS $01 ; 07 ; 15 ; 19 ; 22 ; 23 ; 24 ; 26$ ). Outra participante relatou que, "talvez, a maior dificuldade ou barreira seja o tempo necessário para fazer com que essa nova forma de pensar o processo de ensinagem aconteça" (SUJEITO 36).

$\mathrm{Na}$ categoria aprendizagem, a subcategoria compreensão foi destacada por alguns dos participantes, ao relatarem que: "as leituras são desafiadoras" (SUJEITO 23); "há metodologias complexas de serem aplicadas" (SUJEITO 21); "Não vêm como as metodologias ativas podem ser inseridas em suas áreas de atuação" (SUJEITO 20); "Não sabem quando e como utilizar as metodologias" (SUJEITO 30); "Entender como se planejar as aulas para utilizar as metodologias ativas" (SUJEITO 01).

Quando a dificuldade está relacionada com a aplicação, encontramos duas subcategorias: Habilidade em aplicar as metodologias ativas e as barreiras impostas pelos modelos tradicionais de ensino. Ao compartilharem as suas experiências, os participantes disseram que: "o espaço dedicado à formação de professor é muito restrito e, ainda, voltado exclusivamente para os métodos tradicionais" (SUJEITO 11); "A tendência de mecanizar a aula ainda é muito grande" (SUJEITO 15); "Às vezes temos que trabalhar com métodos tradicionais, para a coisa dar certo" (SUJEITO 14); "Se tivéssemos estudado por meio de metodologias ativas, certamente teríamos outra perspectiva" 
(SUJEITO 03); "Ainda percebo a cultura tradicional muito forte na sala de aula" (SUJEITOS 03, 18 e 25); "Às vezes há insegurança em aplicar as metodologias ativas, pois tudo é muito novo e nem sempre sabemos o passo a passo" (SUJEITO 15); "O desafio é aplicar" (SUJEITO 26), "é motivar e direcionar os alunos para o processo integrado de ensino-aprendizagem" (SUJEITO 35), além de "compreender como cada metodologia pode ser utilizada em cada área de formação" (SUJEITO 04); "É preciso se desvincular dos vídeos da formação tradicional" (SUJEITO 11) e "motivar e despertar os alunos para o uso de metodologias inovadoras" (SUJEITOS 15, 16, 17 e 35).

Percebe-se que a principal dificuldade encontrada pelos docentes ao se planejar e se realizar aulas a partir de metodologias ativas é o tempo, o qual impacta desde a busca do professor por capacitação até o seu planejamento e a realização de aulas inovadoras. A segunda maior dificuldade dos professores está no campo da aplicação, a falta de habilidade. Os docentes sinalizam que precisam desenvolver novas habilidades, especialmente para realizar aulas disruptivas e trazer o estudante para o centro do processo formativo.

Entre jornadas de aulas, pesquisas, atuação no campo profissional e busca por novas aprendizagens, os docentes se veem pressionados e, muitas vezes, inseguros, por não terem tempo para experimentar novas formas de ensino e aprendizagem, essencial ao desenvolvimento de novas habilidades. Também encontramos na fala dos professores questões relacionadas aos conflitos culturais, fazendo, muitas vezes, que o docente opte por permanecer utilizando metodologias tradicionais de ensino para reduzir ou minimizar esse conflito.

Os docentes, sujeitos desse estudo, compartilham entre si as mesmas dificuldades no seu cotidiano. Compreendem que precisam aprender novas formas de ensinar, mas lhes falta tempo para a sua própria formação, além de muitas vezes não compreenderem a relação entre a metodologia e a sua área de formação ou disciplinas com as quais atuam.

Na hora da verdade, momento o qual os docentes utilizarão as metodologias ativas em sala de aula, faltam-lhes habilidades para aplicá-las e, por vezes, deparam-se com metodologias tradicionais tão arraigadas que sentem a necessidade de abortar as inovações propostas.

A subseção seguinte apresenta a percepção dos docentes em relação ao uso das metodologias ativas no processo de ensinagem.

\section{Como os docentes percebem o uso de métodos ativos de ensino e aprendizagem?}

Os docentes, de forma geral, percebem o uso das metodologias ativas no ensino presencial como positivas, descrevendo que melhora o processo de aprendizagem do estudante, amplia as formas de ensinar e de aprender, pode criar uma cultura disruptiva, favorece o aumento do engajamento estudantil etc. 
Por outro lado, também destacam pontos negativos, tais como: desafios com a cultura tradicional permanente em algumas escolas e faculdades, os desafios trazidos pela falta de experiência dos docentes e uma formação deficitária em relação às metodologias ativas no processo de ensino e aprendizagem.

Quadro 4. Percepção dos docentes sobre as metodologias ativas

\begin{tabular}{|c|c|c|c|}
\hline Grupo & Categoria & Subcategoria & Frequência \\
\hline \multirow{7}{*}{$\begin{array}{l}2 \text { - Percepção dos docentes sobre } \\
\text { o uso de métodos ativos }\end{array}$} & \multirow{4}{*}{2.1 - Pontos Positivos } & 2.1.1 - Melhora o processo de aprendizagem & $28 \%$ \\
\hline & & 2.1.2 - Apresenta novas formas de ensino & $38 \%$ \\
\hline & & 2.1.3 - Cria uma cultura disruptiva & $17 \%$ \\
\hline & & 2.1.4 - Aumenta o engajamento estudantil & $17 \%$ \\
\hline & \multirow{3}{*}{2.2 - Pontos Negativos } & 2.2.1 - Cultura tradicional & $63 \%$ \\
\hline & & 2.2.2 - Falta de experiência dos docentes & $11 \%$ \\
\hline & & 2.2.3 - Formação deficitária & $26 \%$ \\
\hline
\end{tabular}

Fonte: Elaborado pelos autores (2018).

O Quadro 4 apresenta as categorias das percepções dos docentes em relação ao uso das metodologias ativas, destacando-se como ponto positivo, as novas formas de ensino, $38 \%$, seguido da melhoria no processo de aprendizagem, $28 \%$. Em relação aos pontos negativos, o ponto mais crítico foi a cultura tradicional existente no ambiente educacional, corroborando o que Moran (2000), ao dizer que ainda ensinamos nos moldes da idade média.

Ao se discutir a percepção dos docentes em relação ao uso das metodologias ativas, nota-se como pontos positivos: a melhoria no processo de aprendizagem, as novas formas de ensino, a criação de uma cultura disruptiva e o aumento do engajamento estudantil. Por outro lado, como pontos negativos, temos: a disputa entre a cultura tradicional e a contemporânea, a falta de experiência docente no uso de métodos inovadores e a formação deficitária, especialmente, quando se trata dos docentes da educação superior.

Sobre a melhoria no processo de aprendizagem, temos as seguintes falas: "As leituras sobre metodologias ativas são maravilhosas" (SUJEITO 13) e "nos fazem pensar em novas formas de mediar saberes com os nossos estudantes" (SUJEITO 26), "promovem o enriquecimento nas mais diversas áreas acadêmicas" (SUJEITO 20); "Os laboratórios rotacionais possibilitam aulas totalmente interativas e motivadoras" (SUJEITO 02); "Realizar uma aula online, por 
meio do WhatsApp, por exemplo, permite-nos ensinar e aprender em qualquer lugar" (SUJEITO 03); "Falar de games no processo de ensinagem é quebrar paradigmas" (SUJEITO 13), pois "dinamizam o processo de ensino e aprendizagem" (SUJEITO 17).

Ainda sobre os pontos positivos, alguns participantes compartilham que tornar o aluno o centro da aprendizagem e selecionar as melhores formas de construir junto com ele os conceitos, "é muito desafiador" (SUJEITO 02), pois nesse "balé de inovação metodológica" (SUJEITO 23), "além de aprender coisas novas e melhorar o planejamento das nossas aulas" (SUJEITO 06), "motiva-nos a continuar evoluindo nossa prática docente" (SUJEITO 28).

Todavia, utilizar metodologias ativas requer planejamento e persistência (SUJEITOS 03 e 14), pois "mesmo sabendo que as antigas técnicas já não se adequam à atual realidade" (SUJEITO 07), ainda "há quem acredite que não se deve fazer uma ruptura no modelo tradicional, mas incluir as metodologias ativas de forma incremental" (SUJEITOS 01 e 07).

As metodologias ativas são uma realidade e "é fundamental que os docentes estejam antenados a elas" (SUJEITO 08), pois "elas permitem a participação dos estudantes na construção do conhecimento além de despertar o seu interesse" (SUJEITO 04) e engajamento. Afinal, é um modelo de educação no qual o aluno não é apenas um mero espectador, mas ele "passa a fazer parte do processo de ensino e de aprendizagem de forma ativa e efetiva" (SUJEITOS 13 e 26), isto porque "as metodologias ativas são estratégias pedagógicas que tornam as aulas mais dinâmicas para o estudante" (SUJEITO 34), colocando "o estudante no centro da produção do saber, reconhecendo suas potencialidades e suas dificuldades, adequando o processo de aprendizagem a realidade do estudante" (SUJEITOS 02, 11 e 12).

Quebrar paradigmas, inserir games na sala de aula, atuar com laboratórios rotacionais, realizar aulas online, são apenas algumas das possibilidades apresentadas pelos docentes. Colocar o estudante no centro do processo formativo também é destacado pelos professores. Mesmo assim, a cultura tradicional ainda se faz presente.

Na próxima seção, apresentamos o engajamento dos docentes em relação ao uso das metodologias ativas.

\section{Como os professores se engajam no processo de transição dos métodos tradicionais de ensino para o uso de metodologias ativas em seu cotidiano?}

Os docentes demonstraram engajamento não apenas durante o curso de extensão, mas em seu cotidiano. Observa-se no Quadro 5 que na categoria afetivo, houve grande satisfação na relação com os pares, seguida da motivação para melhorar a prática docente. Cognitivamente, o engajamento docente se deu por meio do esforço para aprender novas metodologias de ensino e de aprendizagem. E, comportamentalmente, o engajamento estava 
presente na interação entre os pares, proporcionado pela troca de ideias, experiências e opiniões sobre como melhorar a aprendizagem do estudante.

Quadro 5. Engajamento docente

\begin{tabular}{|c|c|c|c|}
\hline Grupo & Categoria & Subcategoria & Frequência \\
\hline \multirow{14}{*}{$\begin{array}{l}3 \text { - Engajamento dos docentes } \\
\text { para aprender novos métodos }\end{array}$} & \multirow{4}{*}{3.1 - Afetivo } & 3.1.1 - Satisfação com as metodologias & $17 \%$ \\
\hline & & 3.1.2 - Satisfação na relação com os pares & $31 \%$ \\
\hline & & 3.1.3 - Motivação em melhorar sua prática docente & $28 \%$ \\
\hline & & 3.1.4 - Curiosidade, Interesse e Expectativas & $24 \%$ \\
\hline & \multirow{5}{*}{3.2 - Cognitivo } & 3.2.1 - Esforço para aprender & $49 \%$ \\
\hline & & 3.2.2 - Investimento para aprender & $16 \%$ \\
\hline & & 3.2.3 - Compreensão das ideias complexas & $12 \%$ \\
\hline & & 3.2.4 - Desenvolvimento de habilidades mentais & $16 \%$ \\
\hline & & 3.2.5 - Resolução de problemas & $6 \%$ \\
\hline & \multirow{5}{*}{ 3.3. - Comportamental } & 3.3.1 - Realização das atividades & $25 \%$ \\
\hline & & 3.3.2 - Interação com os pares & $41 \%$ \\
\hline & & 3.3.3 - Compartilhamento & $8 \%$ \\
\hline & & 3.3.4 - Busca de novos materiais & $5 \%$ \\
\hline & & 3.3.5 - Utilização de metodologias ativas & $21 \%$ \\
\hline
\end{tabular}

Fonte: Elaborado pelos autores (2018).

Os docentes deixaram claro a sua intenção de ler, atualizar-se, buscar novos conhecimentos. Eles já utilizam ou pretendem utilizar as metodologias ativas em suas aulas. Outras evidências de engajamento também podem ser conferidas, quando os professores compartilham os seus conhecimentos e experiências com os seus colegas e familiares, e dedicando-se horas de estudos para melhorar as suas aulas e se reconstruir como docente.

Percebe-se que o engajamento para incorporar novos métodos de ensino e realizar aulas inovadoras está presente entre os docentes, ainda que com dificuldades para se apropriar dos novos métodos ou com que encontrem resistências no seu caminho, promovidas pelos modelos tradicionais de ensino, eles buscam se envolver afetiva, cognitiva e comportamentalmente. 
Os docentes são engajados em melhorar as suas práticas, aprendendo novos métodos de ensino, o que pode ser percebido em suas falas: "Assim que tiver tempo, vou ler materiais que me enriqueçam, momento estou lendo sobre coreografias didáticas e pretendo aplicar com meus alunos" (SUJEITO 02); "Estou baixando e lendo novos materiais" (SUJEITOS 02, 09, 19, 22 e 24); "Estou lendo sobre estilos de aprendizagem para melhorar minhas aulas" (SUJEITO 26).

Muitos relataram que já utilizam ou pretendem utilizar metodologias ativas em suas aulas: "Tento, em minhas aulas, tornar os conteúdos mais palatáveis aos alunos, através de vídeos, rodas de conversa e outras ferramentas (SUJEITO 02); Utilizo algumas metodologias em minhas aulas" (SUJEITOS 01, 03, 06, 07, 10, 11, 15, 17, 23, 26 e 35); "Pretendo tornar minhas aulas mais dinâmicas e obter sucesso na aprendizagem dos estudantes" (SUJEITOS 03, 04, 07 e 10); "Pretendo tornar minhas aulas mais dinâmicas e obter sucesso na aprendizagem dos estudantes" (SUJEITO 15); "Busco adquirir a habilidade de perceber qual a ferramenta mais adequada, conforme a capacidade dos alunos" (SUJEITO 35); e "Pretendo utilizar metodologias ativas em minhas aulas" (SUJEITOS 02, 04, 11, 13, $15,19,22,25,28,30,34$ e 36$)$.

Muitos dos docentes, além de aprenderem e buscarem praticar as metodologias ativas, compartilham com outras pessoas, como pode ser percebido em suas falas: "Debato bastante com os meus colegas sobre o uso de metodologias ativas" (SUJEITOS 17 e 28); "Compartilho o que aprendo sobre metodologias ativas com minha família" (SUJEITOS 18 e 26); e "Busco conhecer novos métodos e depois discutir e compartilhar com os colegas" (SUJEITOS 17, 18, 19 e 25).

Também é possível notar o esforço que os docentes fazem para melhorar as suas práticas, tais como: "Estou me reconstruindo como professor" (SUJEITOS 01, 06, 11, 15, 17, 23 e 26); "Dedico algumas horas do meu dia para o estudo" (SUJEITOS 06, 14, 25 e 26); e "Realizo-me aprendendo e utilizando metodologias ativas" (SUJEITOS 03, 04, 07 e 10).

Percebe-se que o engajamento para incorporar novos métodos de ensino e realizar aulas inovadoras está presente entre os docentes, ainda que com dificuldades para se apropriar dos novos métodos ou com que encontrem resistências no seu caminho, promovidas pelos modelos tradicionais de ensino, eles buscam se envolver afetiva, cognitiva e comportamentalmente.

\section{Considerações finais}

O presente estudo possibilitou aos pesquisadores conhecer as principais dificuldades que os docentes experimentam ao buscarem aprender novos métodos de ensino e aprendizagem para tornar suas aulas mais efetivas e potencializar o desenvolvimento dos seus estudantes. 
A falta de tempo para estudar é um dos maiores vilões, pois a jornada do docente é intensa e complexa. Muitos deles, especialmente os que atuam no ensino superior, têm jornadas triplas, trabalhando como consultor, em indústrias e grandes corporações, e em um dos turnos em sala de aula. Ao chegar em casa, além do cansaço do dia de trabalho, ainda tem as atividades domésticas e familiares. Sem tempo para expandir os seus repertórios didáticos e para se dedicar ao planejamento das suas aulas, muitos não conseguem sair do modelo tradicional de ensino, o qual já não atende mais às demandas do mercado profissional.

Compreender a concepção, o passo a passo e a aplicação de diversas metodologias também se configura como uma das dificuldades encontradas no percurso do docente. Isso ocorre por vários motivos, como por exemplo: formação deficitária na graduação ou pós-graduação, tempo para testar e prototipar, incentivo institucional etc.

Também se apresentaram como dificuldades a falta de habilidade dos docentes com algumas metodologias mais comuns e a cultura tradicional existente nos ambientes de aprendizagem. A habilidade se desenvolve com a prática e a promoção de mudanças culturais leva-se tempo, em ambos os casos, o professor precisará se permitir testar e errar métodos diversos, provocando as mudanças necessárias para uma aprendizagem significativa.

No cenário atual, os professores percebem que as metodologias ativas podem melhorar a aprendizagem dos estudantes, os processos de ensino, criar uma cultura disruptiva e aumentar o engajamento dos alunos. Mas também percebem que a cultura tradicional, a falta de experiência docente e a formação deficitária são pontos negativos que podem dificultar a oferta de um ensino inovador e de qualidade, focado no que é importante para a vida profissional e pessoal do sujeito.

Os docentes demonstraram que estão engajados em um ensino moderno, inovador, disruptivo. Eles estão buscando novos conhecimentos, formações específicas, compartilhando as suas experiências entre seus colegas e familiares. Dedicam horas de estudo, utilizam ou pretendem utilizar metodologias ativas em suas aulas. Estão se reinventando como professores, envolvendo-se emocional, cognitiva e comportamentalmente.

Os resultados aqui apresentados contribuem com a literatura ao discutir sobre a percepção dos docentes sobre uso de metodologias ativas no processo de ensino e aprendizagem e as dificuldades que eles encontram ao confrontar ao modelo tradicional. Ao mesmo tempo, também mostra as formas que eles se engajam para aprimorar as suas técnicas, inovar em suas aulas, motivar os estudantes e continuar evoluindo.

Aqui não foram investigados: a influência das metodologias ativa no engajamento estudantil; as coreografias didáticas utilizadas por esses professores e as coreografias institucionais de onde esses docentes atuam, ficando como sugestões para pesquisas futuras. 


\section{Referências}

ALVES, F. Design de Aprendizagem com uso de Canvas - Trahentem. São Paulo: DVS Editora, 2016.

BACICH, L.; MORAN, J. Metodologias Ativas para uma Educação Inovadora: Uma abordagem teórico-prática. Porto Alegre: Penso, 2018. (Série Desafios da Educação).

BACICH, L.; NETO, A. T.; TREVISANI, F. de M. Ensino Híbrido: Personalização e tecnologia na educação. Porto Alegre: Penso, 2015.

BARDIN, L. Análise de Conteúdo. Lisboa: Edições 70, 2011.

BARROS, M. A. M. Concepções, usos, modelos e estratégias da utilização de dispositivos móveis: uma análise da Aprendizagem Móvel entre professores de Ciências em formação. Tese (Doutorado em Ensino das Ciências) - Universidade Federal Rural de Pernambuco, Recife, p. 241, 2014. https://doi.org/10.31692/2358-9728.iiicointerpdvl.2016.00045

BEER, C. CLARK; K. JONES, D. Indicators of engagement. In: C. STEEL, M.J. KEPPELL \& P. GERBIC, Curriculum, technology \& transformation for an unknown future. Proceedings ascilite Sydney 2010.

CHEN, P. S.D. GONYEA, R. KUH, G. Learning at a distance. In: Journal of online education, 4(3), 2008. Disponível em: http://innovateonline.info/index.php?view=article\&id=438\&action=login. Acesso em: 02 jun. 2018.

CHIN, C. Student-Generated Questions: Encouraging Inquisitive Minds in Learning Science. Teaching and Learning, v. 23, n. 1, jun., 2002, p. 5.947.

CHRISTENSEN, C. M. HORN, M. B. STAKER, H. Ensino Híbrido: uma inovação disruptiva? Clayton Christense Institute, 2013.

CONNELL, J. P. WELLBORN, J. G. Engagement versus Disaffection: Motivated Patterns of Action in the Academic Domain. Rochester, NY: University of Rochester. 1994.

CReSWell, J. W. Projeto de Pesquisa: Métodos qualitativo, quantitativo e misto. 3. ed. Porto Alegre: Artmed, 2010. https://doi. org/10.26512/les.v13i1.11610

DAVIDOFF, L. L. Introdução à Psicologia. 30. ed. São Paulo: Makron Books, 2001.

FERREIRA, A. N. H. Míni Aurélio: O dicionário da língua portuguesa. 8. ed. Curitiba: Positivo, 2011. 
FINLAY, K. A. Quatifying School Engagement: Research Report. National Center for School Engagement. December, 2006. Disponível em: http://schoolengagement.org/wp-content/uploads/2013/12/QuantifyingSchoolEngagementResearchReport-2.pdf. Acesso em: 02 jun. 2018.

FLICK, U. Introdução à pesquisa qualitativa. 3. ed. Bookman/Artmed: Porto Alegre, 2009.

FREDRICKS, J. A. BLUMENFELD, P. C. PARIS, A. H. School Engagement: Potential of the concept, state of the evidence. Review of Education Research, March 1, 2004.

FREIRE, P. Pedagogia do Oprimido. São Paulo: Paz e Terra, 1974.

HORN, M. B.; STAKER, H. Blended: usando a inovação disruptiva para aprimorar a educação. Tradução de Maria Cristina Gularte Monteiro. Porto Alegre: Penso, 2015.

JENKINS, H. Cultura da Convergência. São Paulo: Editora Aleph, 2013.

KRAUSE, K. L. Understanding and promoting student engagement in university learning communities. SHARING SCHOLARSHIP IN LEARNING AND TEACHING: ENGAGING STUDENTS, James Cook University, Townsville, 21-22 set. 2005.

LEAL, E. A. MIRANDA, G. J. CASA NOVA, S. P. de C. Revolucionando a Sala de Aula: como envolver o estudante aplicando as técnicas de metodologias ativas de aprendizagem. São Paulo: Atlas, 2018.

MORAN, J. Educação Híbrida: Um conceito-chave para a educação, hoje. In: BACICH, Lilian; NETO, Adolfo Tanzi; TREVISANI, F. de M. Ensino híbrido: Personalização e tecnologia na educação. Porto Alegre: Penso, 2015.

MORAN, J. Mudar a Forma de Ensinar e de Aprender: transformar as aulas em pesquisa e comunicação presencial-virtual. Revista Interações, São Paulo, v. V, 2000, p. 5.772.

NASCIMENTO, E. R. do et al. Metodologias Ativas e B-Learning: Um estudo de caso com alunos do ensino superior no campo das ciências sociais aplicada. In: CONGRESSO INTERNACIONAL DE TECNOLOGIA NA EDUCAÇÃO, 14.. SENAC, Recife, set. 2016. https://doi.org/10.17648/galoa-cbee-6-29039

OSER, F. K.; BAERISWYL, F. J. Choreografies of teaching: bridging instruction to teaching. In: V. RICHARDSON (Editor). Handbook of research on teaching. 4. ed. Washington: AREA, 2001. p. 1.031-1.065.

PADILHA, M. A. S. et al. Ensinagem na Docência Online: Um olhar à luz das coreografias didáticas. Em Teia - Revista de Educação Matemática e Tecnológica Iberoamericana, v. 1, n. 1, 2010. https://doi.org/10.36397/emteia.v9i2.237651 
PADILHA, Maria Auxiliadora Soares; ZABALZA, Miguel Ángel. Coreografias didáticas no ensino superior: um cenário de integração de Tics na docência universitária. 74 f. Relatório de Pesquisa (Pós-doutorado). Universidade de Santiago de Compostela. Santiago de Compostela/Espanha. 2015. https://doi.org/10.14349/rlp.2019.v51.n3.3

PAULUS, M. P. FRANK, L. R. Ventromedial Prefrontal Cortex Ativation is Critical for Preference Judgments. NeuroReport, v. 14, n. 10, 2003. https://doi.org/10.1097/00001756-200307180-00005

PEIRCE, C.S. The Collected Papers of Charles Sanders Peirce. Cambridge: Harvard University Press, 1958. v. 7-8.

PIMENTA, S. G.; ANASTASIOU, L. das G. C. Do ensinar a ensinagem. In: PIMENTA, S. G.; ANASTASIOU, L. das G. C. (org.). Docência no ensino superior. 2. ed. São Paulo: Cortez, 2005. p. 201-243.

STELKO-PEREIRA, A. C. Escala de Engajamento Escolar: Análise de características psicométricas. Avaliação Psicológica, 2015, 14 (2), pp. 207-212. https://doi.org/10.15689/ap.2015.1402.05

STOVALL, I. Engagement and Online Learning. UIS Community of Practice for E-Learning. 2003. Disponível em: http://otel.uis. edu/copel/EngagementandOnlineLearning.ppt. Acesso em: 02 jun. 2018.

\section{ZABALZA, M. A. Didáctica universitaria. CONFERENCIA PRONUNCIADA EN LA PONTIFICIA UNIVERSIDAD} JAVERIANA DE CALI. 9 fev., 2005.

ZABALZA, M. A. Planificación de la docencia en la universidad. Elaboración de las guías docentes de las materias. Madrid: Narcea, 2010. https://doi.org/10.4995/redu.2012.6034

YIN, R. K. Estudo de Caso: Planejamento e métodos. 5. ed. Porto Alegre: Bookman, 2015.

Recebido em: 30/7/2018.

Aprovado em: 17/10/2018

Publicado em: 31/12/2019.

\section{Endereço para correspondência:}

Ernandes Rodrigues do Nascimento

Rua Orobó, 166 - Arthur Lundgren I

53417-460, Paulista, PE, Brasil 


\section{Autores:}

ERNANDES RodRigues DO NASCIMENTO

Consultor Organizacional, Pedagógico e Educacional. Professor Certificado Google Nível Trainer. Diretor Acadêmico, Professor Universitário,

Conteudista para EAD, Pesquisador, Procurador Institucional e Avaliador de Cursos (INEP). Faculdade Imaculada Conceição do Recife - FICR/ Grupo

UBEC - União Brasileira de Educação Católica.

Orcid: http://orcid.org/0000-0003-3683-6339

E-mail: ernandesrn@gmail.com

Maria Auxiliadora Padilha

Professora associada para atividades de Educação a Distância da Universidade Federal de Pernambuco. Possui graduação em Pedagogia (1997), mestrado em Educação (2001) e doutorado em Educação pela Universidade Federal de Pernambuco (2006). Pós-doutorado pela Universidade de Santiago de Compostela, Espanha.

Orcid: http://orcid.org/0000-0001-7024-6522

E-mail: dorapadilha@gmail.com

Endereço: Universidade Federal de Pernambuco (UFPE)

Av. Prof. Moraes Rego, 1235 - Cidade Universitária

50670-901, Recife, PE, Brasil

\section{Cristiane Lucia Da SiLva}

Graduada em Letras com habilitação em Língua Portuguesa e Espanhola pela Universidade Federal de Pernambuco (UFPE) e laureada do ano 2009.

Graduação em Pedagogia pela Universidade Paulista (UNIP). Atualmente, é Mestra em Educação Matemática e Tecnológica (EDUMATEC) da UFPE.

Doutorado sanduíche pelo EDUMATEC-UFPE em conjunto com a Universidade de Santiago de Compostela (USC).

Orcid: http://orcid.org/0000-0003-1413-4168

E-mail: cristianeletras87@gmail.com

Endereço: Instituto Federal de Educação, Ciência e Tecnologia de Pernambuco (IFPE)

Av. Prof. Luís Freire, 500 - Cidade Universitária

50740-545, Recife, PE, Brasil

Fábio Leandro Melo Ramo dos Anjos

Especialista em Gestão Estratégica de Pessoas - Faculdade Marista e Bacharel em Administração (UNINASSAU). Experiência como:

Secretário Acadêmico e Geral; Pesquisador Institucional, Auxiliar e Pesquisador Educacional Institucional (PI); Coordenador de Ouvidoria e Depositário

do Acervo Acadêmico (DAA). Conhecimento teórico e prático legal nas áreas de educação, administração e Gestão de Pessoas. Membro de Comissão Própria de Avaliação (CPA). Membro dos Conselho Acadêmicos e Administrativos. Gestor de Projetos (PMO). Consultor Educacional e Empresarial.

Orcid: http://orcid.org/0000-0001-9013-5846

E-mail: fabioanjoss@gmail.com

Endereço: Faculdade Imaculada Conceição do Recife (FICR)

Av. Caxangá, 3841

52071-420, Recife, PE, Brasil 